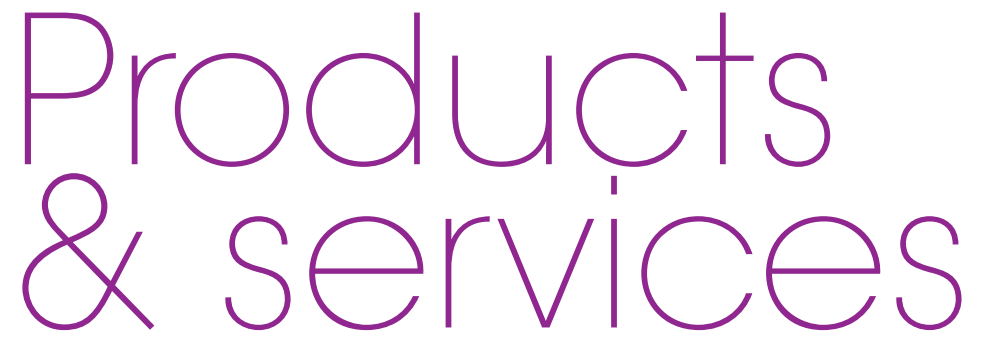

Product news is provided as a service to readers using text and images from
the manufacturer, supplier or distributor and does not imply endorsement

by BDJ Team. Normal and prudent research should be exercised before

\section{ACT EARLY AGAINST GUM DISEASE}

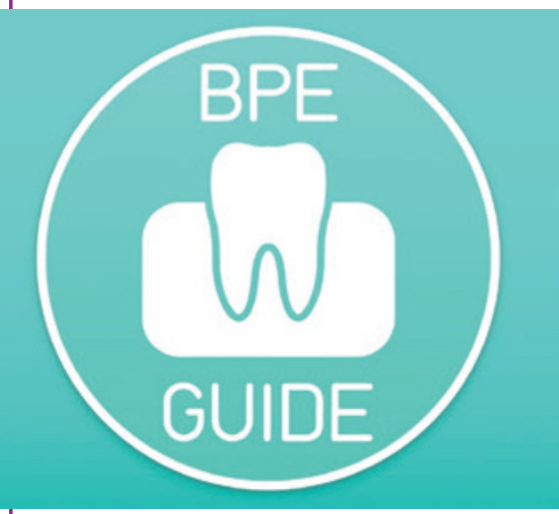

As undiagnosed and untreated

periodontal disease is one of the fastest

growing areas of litigation and complaints

in dentistry, acting early against gum

disease has never been so important.

The Dental Defence Union (DDU)

recommends use of the Basic Periodontal

Examination (BPE) to help reduce the

risk of a claim for failing to diagnose

periodontal disease.

First produced by the British Society

of Periodontology in 1986, ${ }^{2}$ the BPE is a

simple screening tool to identify your

patient's periodontal status. All patients

should have the BPE performed and their

score recorded, which will enable you, as

a dental professional, to advise them on

how to best protect their gum health.
With over 30 years' gum care expertise, Corsodyl is committed to helping dental professionals to identify the signs of periodontitis as early as possible. Corsodyl has recently launched two free materials to help in the identification and prevention of gum disease, using the BPE.

Gum Health - A Practitioner's Guide is a handy booklet designed to refresh your knowledge of the BPE, as well as the signs, symptoms and risk factors. Visit www.gskdentalprofessionals.co.uk to request your free copy.

Compatible with iPhones and iPads, the Corsodyl Guide to BPE \& Gum Health mobile app is designed to be a quick reference tool for the BPE. It features a description and clinical image of each BPE code and a summary of recommended treatment. To download the free app, visit the iTunes App Store and search 'BPE app'
Dental Protection. Exercises in risk
management. Periodontal monitoring.
Available at http: //www. dentalprotection.
org/adx/aspx/adxGetMedia
aspx?DoclD=1363 (accessed 12 May 2014)
British Society of Periodontology. Basic
Periodontal Examination (BPE) guidance,
2011 . Available at http: //www.bsperio.org
uk/publications/downloads/39_143748_
bpe201 1.pdf (accessed 12 May 2014).

\section{OFFER \\ PERSONALISED \\ ORAL CARE KITS}

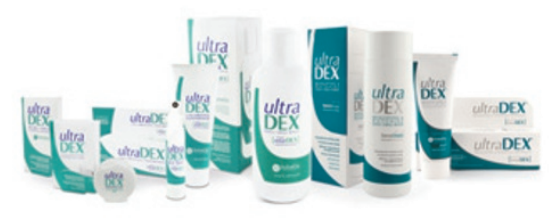

In aesthetic dentistry, preventive maintenance is one of the keys to increasing the success rate of cosmetic treatments and decreasing risks of failure due to poor oral hygiene. To achieve an unsurpassed level of oral hygiene leading to excellent gum health, the challenge is to eliminate odour causing Volatile Sulphur Compounds (VSCs) and bacteria associated with the build-up of plaque, tooth decay and gum problems UltraDEX bridges the gap between professional and home care. With clinically proven technology, powered by stabilised chlorine dioxide, UltraDEX works with the natural oral pH, helps protect against plaque, restores natural whiteness by gently oxidising organic stains and instantly eliminates bad breath compounds (VSCs) for 12 hours.

Free from alcohol and sodium lauryl sulphate, the UItraDEX Performance Oral Care range is gentle, effective and safe for long term daily use. Suitable for use in the surgery and at home. UItraDEX guarantees exceptional oral health on your patient's visits and for 363 days a year when not in your care.

To encourage patient compliance and help enhance treatment outcomes UltraDEX Oral Care Kits have been developed, which can be personalised with practice details. For further information, visit wWw. periproducts.co.uk oremaildental@periproducts.co.uk.

\title{
UP-TO-DATE ADRENALINE INJECTOR
}

Med Systems Ltd has launched Emerade - a new design of adrenaline auto-injector - the first 'pen' to follow both the latest MHRA recommendations and the UK Resuscitation Council's guidelines.
To maximise the likelihood of achieving the necessary depth of intra-muscular injection, the new Emerade design features longer intra-muscular needles. The simplicity of its use can be seen in a short video on the Emerade website: wuw. emerade.com/instruction-video

In order to reduce costs to the NHS, Emerade is manufactured with a 30-month shelf-life and is available on NHS prescription across the UK.

Visit www.emerade.com to find out more

If you would like to promote your products or services direct to the dental industry in BDJ Team, just give Steve Brown a call on 02078434724 or drop an email to stephen.brown@nature.com. 